\title{
Comparative Economic Analysis of Offshore Platform Decommissioning Methods
}

\author{
Saturday Ebigenibo Genuine ${ }^{1}$, Amusat Waheed Olaide ${ }^{2}$ \\ ${ }^{1}$ Department of Mechanical Engineering, University of Port Harcourt, Port Harcourt, Nigeria \\ ${ }^{2}$ Offshore Technology Institute (OTI), University of Port Harcourt, Port Harcourt, Nigeria
}

Email address:

ebigenibo.Saturday@uniport.edu.ng (S. E. Genuine), satebi $a$ yahoo.com (S. E. Genuine)

To cite this article:

Saturday Ebigenibo Genuine, Amusat Waheed Olaide. Comparative Economic Analysis of Offshore Platform Decommissioning Methods. Engineering and Applied Sciences. Vol. 4, No. 1, 2019, pp. 11-15. doi: 10.11648/j.eas.20190401.12

Received: January 21, 2019; Accepted: February 25, 2019; Published: March 18, 2019

\begin{abstract}
In this work, three basic approaches for removing offshore facilities-piece small, piece large and single lift methods were considered and applied to six different platforms (A, B, C, D, E and F) using data obtained from Proserv Offshore. The aim is to ascertain the decommissioning costs, salvage values and the onshore real value of each platform in the future when decommissioning will take place. The decommissioning cost for piece large obtained was used to generate piece small and single lift decommissioning costs exploiting analytical method/using relevant relations. The annual interest rate was derived from the data which was provided for 2010 and 2014 and the future decommissioning costs for each method was estimated for all the six platforms. The decommissioning costs (in million US dollars (M\$)) for the six platforms A, B, C, D, E and $\mathrm{F}$ with respective weights 2012, 15128, 42100, 54660, 112392 and 130178 tons for piece small method are respectively 25.1, 164.5, 851.7, 1321.3, 5051.4 and 6196.5. The salvage values (in M\$) for these platforms using the piece small method are $105.76,217.87,468.04,570.64,1099.47$ and 1169.77 respectively while the onshore real values after decommissioning are $80.66,53.37,-383.66,-750.66,-3951.93$ and -5026.73 . Results were also obtained for the other two methods. Comparing the results of the different methods it was observed that the most appropriate decommissioning option for Nigeria offshore is piece large with decommissioning cost, salvage Value and onshore real value of $16.7 \mathrm{M} \$, 100.2 \mathrm{M} \$$ and $83.5 \mathrm{M} \$$ respectively for platform A.
\end{abstract}

Keywords: Decommissioning Cost, Piece Large, Piece Small, Salvage Value, Single Lift, Onshore Real Value

\section{Introduction}

Decommissioning of offshore platform is the partial or complete removal and disposal of outdated installations at the end of their life of operation. It is a huge process that can last several years. In 2009, Minerals Management Service (MMS) realises that all the platforms located in the pacific outer continental shelf (POCS) will reach the end of their useful life between 2015 to 2030 time period at which point they must be decommissioned and either removed or transferred to alternate use. Piece-small method of decommissioning is defined to involve breaking down of offshore platforms in smaller sections not greater than 20 tons [1]. This option limits the size of components that can be decommissioned for either re-use or re-sale. Piece large involves the removal of offshore platform in sections greater than 20 tons but not more than 5000 tons. It can allow re-use of assemblies up to the size of complete module. Single lift being the third option is the removal of the platform topsides as a single entity, with the jacket also being removed in a similar manner. With this approach, there is high tendency for the full platform topsides to be reused in a new place or assemblies up to module size could be re-used after dismantling in the shore [1].

Before decommissioning activities is embarked upon, it is pertinent to ensure that the platform is fully ready for pick by the Heavy Lift Vehicle (HLV). For this to be achieved, where drilling rig is installed, it must be removed, topside module should be ready for removal, the processing equipment must be free of hydrocarbon fluids and the deck has to ready to be detached from the steel jacket [2]. Different approaches to decommissioning and the decommissioning of large offshore structures as well as legal issues and regulations concerning 
decommissioning have been investigated [3-7]. The deducibility of decommissioning costs / assignment of decommissioning responsibility and other relevant issues concerning decommissioning have also been considered [8]. Legal considerations for offshore oil and gas based infrastructure decommissioning have been addressed, also, reliable and innovative approach for decommissioning have been presented [9-10].

Platform decommissioning need approval from regulatory agencies and a number of issues associated with decommissioning alternatives. California Natural Resources Agency initiated 3-phase process to investigate issues on decommissioning alternatives together with the costing analysis [11]. Decommissioning costs are high and decommissioning cost estimations have been carried out [12]. Also, means of reusing offshore jacket platforms have been studied and presented [13]. Burns and McDonnell [14] posited that offshore facilities location that resulted in the greatest total distance should be considered as part of the basis of the decommissioning cost estimates. There are also studies concerning leaving offshore platforms as reefs for the natural habitat instead of decommissioning [15-16]. As the age of an offshore structure increases its structural integrity decreases and chances of failure set in unless it is properly maintained [17]. Thus, there is need to decommission platforms quickly and reuse as many parts as possible. But at present, no decommissioning has been carried out in the Nigerian oil and gas sector and cost implications associated with different decommissioning methods are not available. This work thus seeks to provide such relevant information for the nearest future.

\section{Materials and Methods}

The most cost-effective method for decommissioning operations that could be applicable to six different platforms in Nigeria is sought. Data about decommissioning is first obtained from the field for different platforms and applied to the platforms considered based on the total weight (in tons) of the platforms. The data is obtained for two different years (2010 and 2014) and the annual increase in decommissioning cost is estimated. The decommissioning cost for a future time is estimated based on the annual increase in decommissioning cost. The data available in one decommissioning method is transferred to the other decommissioning methods using basic assumptions and information obtained from those with good experience in decommissioning operations.

\subsection{Decommissioning Data from the Field}

The six platforms considered are in the Eastern operational zone of Nigeria but here represented with letters A, B, C, D, $\mathrm{E}$ and $\mathrm{F}$. Cost of decommissioning from piece large method for the years 2010 and 2014 were obtained [18] for six different fields outside Nigeria which total weight fall in the category of the six fields considered in this research and are presented in Table 1.
Table 1. Input decommissioning data per platform.

\begin{tabular}{llll}
\hline \multirow{2}{*}{ Platform } & \multirow{2}{*}{ Platform weight (ton) } & \multicolumn{2}{l}{ Decommission Cost MS } \\
\cline { 3 - 4 } & & $\mathbf{2 0 1 0}$ & $\mathbf{2 0 1 4}$ \\
\cline { 3 - 4 } & 2012 & 12.0 & 16.7 \\
\hline I, A & 15128 & 29.6 & 34.4 \\
II, B & 42100 & 67.9 & 73.9 \\
III, C & 54660 & 80.3 & 90.1 \\
IV, D & 112392 & 149.6 & 173.6 \\
V, E & 130178 & 155.9 & 184.7 \\
VI, F & & & \\
\hline
\end{tabular}

\subsection{Data Analysis}

The data presented in Table 1 is the cost of platform decommissioning using piece large (PL) method. Platform weights in tons and their corresponding decommissioning costs are provided. The corresponding costs in piece small (PS) and single lift (SL) methods are to be derived from this data. This is the first task. Subsequent analysis involves projecting the decommissioning cost in in the next future where actual decommissioning will take place in some of the platforms considered. The different decommissioning costs are then compared to see the kind of decommissioning costs that will be economically viable for the different platforms and to ascertain the decommissioning costs to be incurred when the platforms considered and similar platforms will be decommissioned in the future.

$\mathrm{ABB}$ [1] propounded the following tonnage limits for different decommissioning options:

$$
\begin{gathered}
\text { Piece small (PS) }-x \leq 20 \text { tons } \\
\text { Piece large (PL) }-20 \leq x \leq 5000 \text { tons } \\
\text { Single lift (SL) - } 5000 \leq x \leq 48,000 \text { tons }
\end{gathered}
$$

where the term $x$ represents the possible tonnage of platform applicable to decommissioning methods. Other considerations arising from probable severity of damage in each decommissioning option includes:

Piece small (less damage) - 5\% loss; Piece large (moderate damage) - 10\% loss and Single lift (more damage) - 20\% loss. Using proprietary information from the agency who has been involved in decommissioning right from the onset informs the following basic assumptions:

i. Using piece small when the load is less than 20 tons, $0.5 \%$ of the cost per ton is incurred on each additional crane trip

ii. If the load is less than 48,000 tons, using a single lift should incur additional cost of $10 \%$ of that of piece large decommissioning cost

iii. For load greater than 48,000 tons, the cost for single lift is $90 \%$ of piece large value.

Thus, the decommissioning cost for PS when the load is greater than 20 tons derived from PL decommissioning cost is given by Equation (4),

$$
\mathrm{C}_{\mathrm{PS}}=\mathrm{C}_{\mathrm{PL}}+\left\{\frac{5}{100} * C_{P T} * N_{T} * L\right\}
$$

where $\mathrm{C}_{\mathrm{PL}}$ is decommissioning cost for $\mathrm{PL}, \mathrm{C}_{\mathrm{PS}}$ is decommissioning cost for $\mathrm{PS}, \mathrm{C}_{\mathrm{PT}}$ is the required 
decommissioning cost per ton, $\mathrm{N}_{\mathrm{T}}$ is the number of trips and $\mathrm{L}$ is the load (in tons). In the same vein, cost for SL option for the load less than 48,000 tons will be $10 \%$ higher as a result of factors like cost of hiring crane, technical know-how among others. Whereas for load above 48,000 tons, there will be a reduction factor of 0.9 compared to piece large decommissioning cost. The SL decommissioning cost derived from PL cost for the two cases are given in Equations (5) and (6) respectively:

$$
\begin{aligned}
C_{S L} & =1.1 \mathrm{C}_{\mathrm{PL}} \\
C_{S L} & =0.9 \mathrm{C}_{\mathrm{PL}}
\end{aligned}
$$

where $\mathrm{C}_{\mathrm{SL}}$ is the SL decommissioning cost. Cost incurred in decommissioning a given offshore platform (DC) equals to the predetermined $15 \%$ cost of the platform (PC);

$$
\mathrm{DC}=0.15 \mathrm{PC}
$$

Thus, the cost of each platform obtained from the decommissioning cost value available is in the form;

$$
P C=\frac{D C}{0.15}
$$

The platform salvage values (SV) are taken as 95\%, 90\% and $80 \%$ of platform costs for piece small, piece large and single lift respectively based on the damage values provided. Platform onshore real value (ORV) and salvage value after decommissioning are related as,

$$
O R V=S V-D C
$$

The decommissioning cost in the future (2030 in this case) can be obtained from the present value in the form,

$$
\mathrm{FV}=\mathrm{PV}(1+r)^{n}
$$

where $\mathrm{FV}$ is the future value, $\mathrm{PV}$ is the present value, $\mathrm{r}$ is annual interest rate (\%), $\mathrm{n}$ is duration (years). The annual interest rate is obtained from the decommissioning cost data for 4 years as,

$$
\mathrm{r}=\left\{\frac{D C_{2014}}{D C_{2010}}\right\}^{1 / 4}-1
$$

The analysis was applied to the data provided in Table 1 and most suitable decommissioning method for the different platforms is presented in the results in the next section.

\section{Results and Discussion}

The decommissioning costs for the six platforms using the PL method as presented in Table 1 are transferred to PS and SL decommissioning costs and the three sets of results are presented in Figure 1. The PS decommissioning cost is the highest for all the platforms. It dwarfs the other decommissioning costs. Comparison between the PS and PL decommissioning costs is presented in Figure 2 for the purpose of clarity. The PS decommissioning cost is suitable for loads below 20 ton but the least platform weight considered here is 2012 ton hence the decommissioning cost derived from the PL cost values are very large.

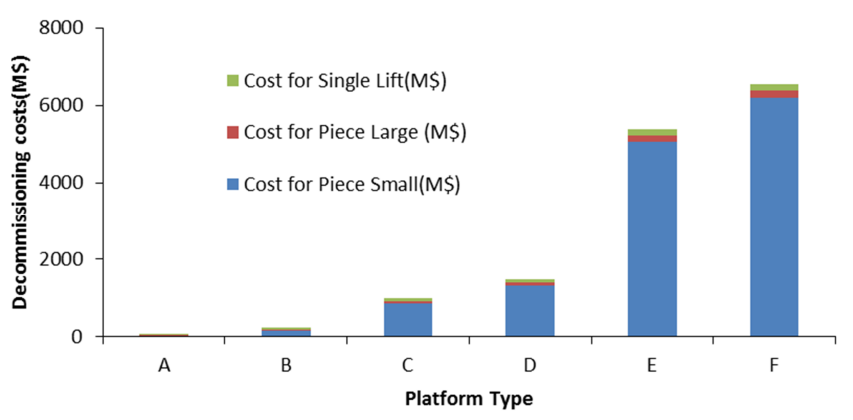

Figure 1. Comparison of PS, PL and SL decommissioning costs.

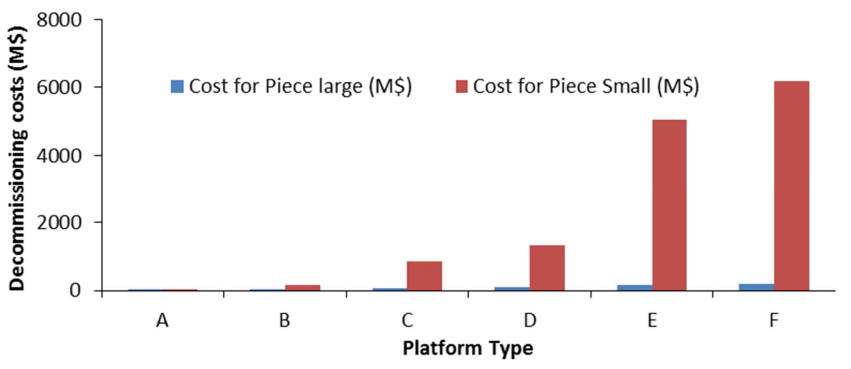

Figure 2. Comparison of PL and PS decommissioning costs.

Table 2. General comparison of PS, PL and SL decommissioning costs.

\begin{tabular}{llll}
\hline Platform & $\begin{array}{l}\text { Platform weight } \\
\text { (ton) }\end{array}$ & $\begin{array}{l}\text { Cost for Piece } \\
\text { large (MS) }\end{array}$ & $\begin{array}{l}\text { Cost for Single } \\
\text { Lift (MS) }\end{array}$ \\
\hline A & 2012 & 16.7 & 18.37 \\
B & 15128 & 34.4 & 37.84 \\
C & 42100 & 73.9 & 81.29 \\
D & 54660 & 90.1 & 81.09 \\
E & 112392 & 173.6 & 156.24 \\
F & 130178 & 184.7 & 166.23 \\
\hline
\end{tabular}

The decommissioning costs for PL and SL methods are comparable as shown in Table 2. SL decommissioning is suitable for platform weight greater than 48000 ton. Thus, from Table 2, the decommissioning cost using single lift method is higher than the PL method for platforms A, B and $\mathrm{C}$ where the platform weights are each less than 48000 ton. For platforms D, E and F where the platform weights are each greater than 48000 ton, the single lift method is more economical to apply as the decommissioning cost associated with the single lift method is lower for each of the platforms.

The worth of platform at the time of decommissioning which is referred to as platform Cost (PC) and the Salvage Value for the three decommissioning methods are provided in Table 3.

Table 3. Comparison of salvage value for PS, PL and SL.

\begin{tabular}{lllll}
\hline Platform & $\begin{array}{l}\text { Platform } \\
\text { cost (MS) }\end{array}$ & $\begin{array}{l}\text { SV for PS } \\
\text { (M\$) }\end{array}$ & $\begin{array}{l}\text { SV for PL } \\
\text { (MS) }\end{array}$ & $\begin{array}{l}\text { SV for SL } \\
\text { (MS) }\end{array}$ \\
\hline A & 111.33 & 105.76 & 100.2 & 89.06 \\
B & 229.34 & 217.87 & 201.4 & 183.47 \\
C & 492.67 & 468.04 & 443.4 & 394.14 \\
D & 600.67 & 570.64 & 540.6 & 480.54 \\
E & 1157.34 & 1099.47 & 1041.6 & 925.87 \\
F & 1231.34 & 1169.77 & 1108.2 & 985.07 \\
\hline
\end{tabular}


The platform costs depends on the weight of the platforms and hence the values increases from platform A to F. PS method of decommissioning enables large quantity of recyclable materials ranging from high grade steel to other machinery to be in good shape for re-use, hence PS decommissioning methods provides the highest salvage values. But the real values of platform at the shore after decommissioning referred to as onshore real value (ORV) for piece small method is not economical as it demands high decommissioning cost as shown in Figure 3. Hence, the PS decommissioning method not recommended for any of the platforms considered. Using the PL and PS methods, substantial asset values could be obtained.

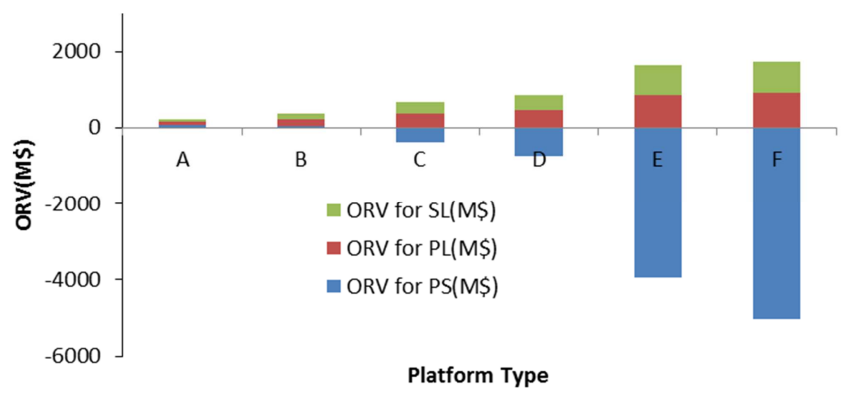

Figure 3. Comparison of ORV for PS, PL and SL decommissioning methods.

The onshore real values are shown distinctively for platforms $\mathrm{A}$ and $\mathrm{F}$ in Figures 4 and 5. For platform A where the platform weight is low, the ORV for the PS method is greater than that of the SL method but smaller than that of the PL method. For platform F, the PS method gives negative ORV while those of the other two methods are comparable but the PL method gives higher value.

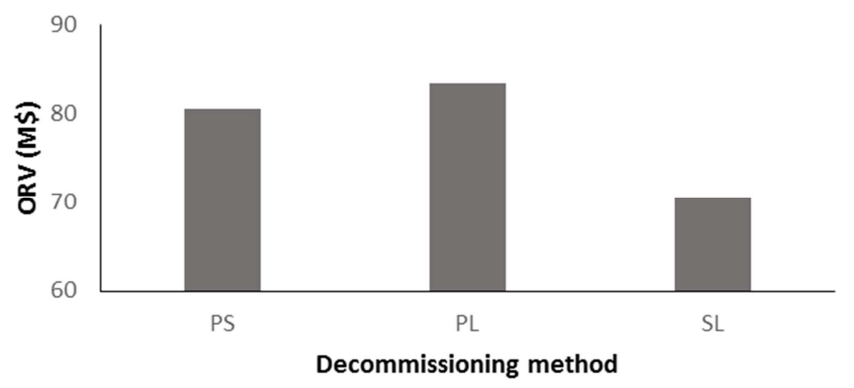

Figure 4. Comparison between onshore real value for PS, PL and SL in platform $A$.

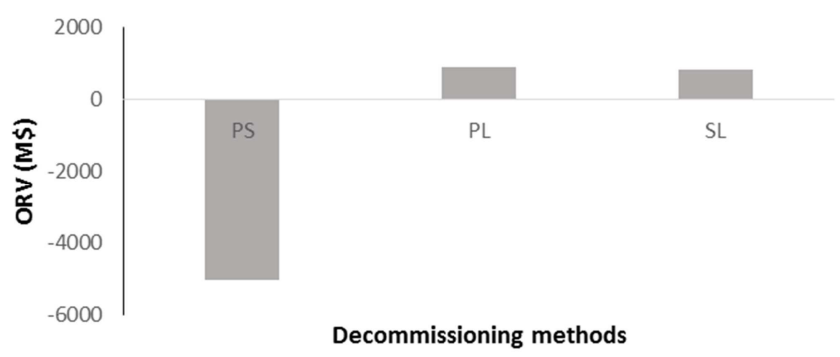

Figure 5. Comparison between onshore real value for PS, PL and SL in platform $F$.

\section{Conclusion}

In this study, three decommissioning methods (piece small, piece large and single lift) were applied to six existing platforms in Nigeria using decommissioning cost data from Proserv offshore for two different years to ascertain the decommissioning costs, salvage values and the onshore real value of each platform in the future when decommissioning will take place. It was observed from the results that piece large is the most economically feasible method for Nigeria situation followed by single lift option. The piece small method gives the highest salvage value but gives extremely high decommissioning cost values for five of the platforms.

No decommissioning of offshore platforms has taken place in Nigeria so far, but the results obtained in this work will give platform owners relevant information, especially decommissioning costs they will incur in the future and hence properly plan ahead. This work did not consider limitations and the impacts of different decommissioning options on the environment. Thus, further research is required to give detail account of limitations surrounding different decommissioning options. Also, the relative impacts on the environment with the usage of the different decommissioning methods need to be investigated.

\section{References}

[1] ABB (2015). Offshore Oil and Gas Decommissioning, A Technical Report. Available at: https://library.e.abb.com/public/d689c2f70f0c447586610ac56 6c9aa7e/ ABB- Offshore- Oil- and-Gas-Decommissioning2015.pdf. Accessed on 20/08/2018.

[2] ICF Incorporated (2018). Decommissioning Methodology and Cost Evaluation. Available at: https://www.bsee.gov/sites/bsee.gov/files/tap-technicalassessment-program/ 738aa. pdf. Accessed on 25/08/2018.

[3] Fowler, A. M., Macreadie, P. I., Jones, D. O. B. and Booth, D. J. (2014). A Multi-Criteria Decision Approach to Decommissioning of Offshore Oil and Gas Infrastructure, Ocean and coastal Management, Vol. 87, pp. 20-29.

[4] Wilkinson, W. B., Bakke, T., Clauss, G. F., Clements, R. Dover, W. D. Rullkötter, J. and Shepherd, J. G. (2016). Decommissioning of Large Offshore Structures - The Role of an Independent Review Group (IRG), Ocean Engineering, Vol. 113, pp. 11-17.

[5] Techera, E. J. and Chandler, J. (2015), Offshore Installations, Decommissioning and Artificial Reefs: Do Current Legal Frameworks Best Serve The Marine Environment?, Marine Policy, Vol. 59, pp. 53-60.

[6] Fam, M. L., Tan, H. K., Konovessis, D. and Ong, L. S. (2017). A Review of Offshore Decommissioning Regulations in Three Countries: Strengths and Weaknesses, ASME 2017 36th International Conference on Ocean, Offshore and Arctic Engineering, Trondheim, Norway, June 25-30, 2017.

[7] Fam, M. L., Konovessis, D., Ong, L. S. and Tan, H. K. (2018). A review of offshore decommissioning regulations in five countries - Strengths and weaknesses, Ocean engineering, Vol. 160, pp. 244-263. 
[8] Parente, V., Ferreira, D., dos Santos, E. M. and Luczynski, E. (2006). Offshore Decommissioning Issues: Deductibility and Transferability, Energy Policy, Elsevier, Vol. 34, Issue 15, pp. 1992-2001.

[9] Chandler, J. White, D. Techera, E. J., Gourvenec, S. and Draper, S. (2017). Engineering and Legal Considerations For Decommissioning Of Offshore Oil and Gas Infrastructure in Australia, Ocean Engineering, Vol. 131, pp. 338-347.

[10] Friederichs, C., Dibello, F., Tignanelli, A. and Garzia. (2015). Reliable and Innovative Approach for Decommissioning Study of Oil \& Gas Plants, in the Proceedings of Offshore Mediterranean Conference and Exhibition, 25-27 March, 2015, Ravenna, Italy.

[11] Bressler, A. and Bernstein, B. B. (2015). A Costing Model For Offshore Decommissioning in California, Integrated Environmental Assessment and Management, Vol. 11, Issue 4, pp. 554-563.

[12] Kaiser, M. J. and Liu, M. (2014). Decommissioning Cost Estimation in the Deep Water U.S. Gulf of Mexico - Fixed platforms and Compliant Towers, Marine Structures, Vol. 37, pp. 1-32.

[13] Lun, N. K., Zawawi, N. A. W. A. and Liew, M. S. (2012). Conceptual Framework: Semi-PSS for Sustainable Decommissioning of Offshore Platforms in Malaysia, 2012 International Conference on Statistics in Science, Business and Engineering (ICSSBE), 10-12 Sept. 2012, Langkawi, Malaysia.

[14] Burns \& McDonnell (2018). Decommissioning Plan and Decommissioning Obligation Cost Evaluation. Available at: https://www.mcleancountyil.gov/ Document Center/ View/11312/AP-EX-8--Revised. Accessed on 20/08/2018.

[15] Macreadie, P. I., Fowler, A. M., Booth, D. J. (2012). Rigs-toReefs Policy: Can Science Trump Public Sentiment? Front Ecol Environ, Vol. 10, pp. 179-180.

[16] Macreadie, P. I., Fowler, A. M., Booth, D. J. (2011). Rigs-toReefs: Will the Deep Sea Benefit from Artificial Habitat? Front Ecol Environ, Vol. 9, pp. 455-461.

[17] Stacey, A., Birkinshaw, M. and Sharp, J. (2008). Life Extension Issues for Ageing Offshore Installations, International Conference on Offshore Mechanics and Arctic Engineering, (June), pp. 1-17.

[18] Proserv Offshore (2010). Decommissioning Cost Update for Removing Pacific OCS Region Offshore Oil and Gas Facilities, Minerals Management Service Report MMS M09P C00024. Available

https://www.bsee.gov/sites/bsee.gov/files/tap-technicalassessment-program//646aa.pdf. Accessed on 22/08/2018. 